\title{
Project management interactive learning and project oriented learning organizations
}

\author{
J. L. Cano, M. J. Sáenz, J.A. Cebollada \\ Project Engineering Area, Faculty of Engineering, \\ University of Zaragoza, \\ c/ María de Luna, 3 - 50015 Zaragoza (SPAIN) \\ Tel: 34 - $976-761910$ \\ Fax: 34 - 976 - 761861 \\ e-mail:jlcano@posta.unizar.es,mjsaenz@posta.unizar.es
}

\begin{abstract}
After classifying the types of knowledge in project management oriented companies, the paper presents the requirements of project oriented learning organizations, with special attention to the aspects of tacit knowledge acquisition and experimentation. Two experiences are described in relation to the use of simulation games as training and experimenting tools both in the academic environment and industry.

The concept of a Laboratory for project management processes simulation with the aim of capturing the project professionals' behavior is presented. After that, we discuss about the current state of the work related to the development of a data acquisition module, specially designed for an existing simulation game.
\end{abstract}

Keywords

Project management, Simulation games, Learning organization

\section{INTRODUCTION}

The increasing adoption of Project Management by industry, together with the increase in the demand for the PM certification, has meant a surge in training necessities in this field. PM training on as such requires an important practical component. It would be unachievable if the only way to transmit it were by means of one's own experience gained in contact with real projects. 
Tools are required to allow us to act as close as possible to real situations and they must be accessible to a high number of practitioners, so that we do not have to pay for the costs of the errors we commit when making wrong decisions. This role is carried out by Project Simulation Games in PM training programs. These tools allow, individually or in group, to interact actively and dynamically with a "living" project that we have to manage. A wide variety of these games are available in the market (SIMULTRAIN, Virtual Experience, The Planning Game, PROSIGA, etc.) most of them oriented towards being internal training tools for neophytes in Project Management.

After this first reference to the instrumental aspect of games as an effective aid in the process of training new Project Managers, the topic of PM training takes us to a second consideration included in the title: not only does the individual learn, but the company itself as a whole. According to Garvin (1993), a Learning Organization would be that one which is qualified in acquiring, creating and transferring knowledge, by itself. Based on this knowledge, the company is transformed with the aim of reflecting and implementing what has just been learnt. Nonaka and Takeuchi (1995) have established a model that refers to the development of knowledge in the most advanced Japanese companies. It is termed the Spiral of Knowledge. This model presents the transmission of the best professional's know-how to the collective knowledge of the company, by showing the method followed by the expert, and disclosing its use to the rest of the company. We will now see a perspective of what the cycle of knowledge would be in a project oriented company according to Nonaka and Takeuchi's model.

\section{TYPES OF KNOWLEDGE IN THE PROJECT ORIENTED COMPANY}

In companies oriented to work by projects, the transmission of knowledge will be presented in the following type of cases:

\section{a) Transmission of tacit know-how:}

A young professional knows that a member of the organization is an expert in how to manage the start up of certain projects. When required by the novice, the expert supports him as a mentor, by interchanging ideas on problems that come up.

The transmission of this type of tacit know-how is characteristic of the kind of relationship that implies the internal recognition of "autoritas" in a determinate subject, and of the customized transmission of this knowledge to those who ask for advice.

\section{b) Transforming the non verbalization into an explicit knowledge:}

The aforementioned expert, as a company representative and thanks to his valuable skills in this field, has managed a good number of negotiations related to civil engineering works. After observing him, we have been able to prepare and review, with the expert, a guide which would help all the junior negotiators. Additionally, we have gathered a series of cases from the expert in order to prepare the "script" of an audio-visual aid that would make the training task easier. In this example we 
can externalize and make visible the non verbal knowledge of an individual and transfer it to the group.

Another example of this type of knowledge transformation would be a mechanized system for the preparation of estimates for injection moulds for plastic components. These estimates require the synthesize, in a short period of time, of previous experiences in moulds already developed, and eventually in mould budgeting (design, manufacturing \& testing). Having a mechanized system based on the historical data collected from the control of costs of previous moulds manufactured, would allow us to make a quick search of similar precedents. It would also provide us with a reliable estimate based on parameters which are typical of the design and the manufacturing process of the moulds. The whole set of previous works becomes accessible by means of this available explicit knowledge. This knowledge transformation would imply the design and implementation of a model built up from scratch from the data available and the tacit knowledge of the current people involved in budgeting tasks.

\section{c) Using existing explicit knowledge:}

Here, we do not develop new knowledge as such, the result is new but the work method is already known. An example of this situation would be the preparation of a new mould offer, using the mechanized system mentioned before.

\section{d) From explicit knowledge to tacit knowledge:}

The estimate system introduced becomes well-known by the group in charge of preparing offers. Those who used to have to frequently consult the manual end up totally internalizing the new procedure.

According to Riis (Riis et al, 1996), the Simulation Games, commonly accepted as a means of simulating reality by the participant, pass through the phases of socialization, externalization and internalization of the Spiral of Knowledge of Nonaka. In this way, the games allow us to show tacit knowledge related to the field of industrial organization, and reveal situations, in a process of learning, that cannot be shown in any other way.

\section{WHAT DO WE MEAN WHEN WE TALK ABOUT A PROJECT ORIENTED COMPANY THAT ACTS AS A LEARNING ORGANIZATION?}

- According to Garvin, there are certain elements present in Learning Organizations:

- Systematic method to confront problems.

- Ability to learn from clients.

- Eagerness to introduce best practices from other sectors.

- Ability to transfer knowledge within the organization, quickly and effectively.

- Ability to analyze past experiences.

- Spirit to learn by experimenting. 
From the point of view of project oriented companies:

- The work methods, the tools and attitudes for dealing with problems become something specific, a kind of "meta-language" characteristic of each company. This allows employees to work together more effectively, assimilating beforehand the way to solve problems.

- The importance of relations with the client throughout the project and their impact on the project's success (Pinto and Slevin, 1989) leads us to consider the client as a very important point where knowledge can be found. It is necessary to know about his/her needs, to raise schemes to participate in joint developments. And lastly, it is also important for clients to participate in the post-mortem analysis of the projects that have been developed for them.

- From the point of view of the need to provide the best, it would not make sense if our "Project Factory" did not have the most developed technology in management of business processes associated to the development of the projects. Knowing the actual situation of the sub-processes of our PM company and discovering the best practices to be considered as standards from other sectors is of utmost importance. Specific $R+D$ projects have been developed by Gareis (Gareis and Huemann, 1998) for the benchmarking of the sub-processes of project start, project controlling \& project close up.

- It is not worth developing or to obtaining knowledge if we are not capable of making the whole organization, assimilate it at the same pace in which it is given. To assimilate does not mean understanding or knowing. Here, it means a daily practice, a commitment, to put it into practice throughout all of the organization. The lessons we have learned in the post-mortem evaluation of the last project developed have to be incorporated in the next. The post rotation and the incentive system are usually two of the most used measures in this transference effort. It is curious that, unlike Japanese companies, (where the enthusiastic contribution of the individual to the knowledge base of the company is assumed) Hansen (Hansen et al, 1999) presents different incentive systems that are used by important American management consulting companies for encouraging people to participate in knowledge sharing.

- Analysis of former experiences. I remember a shipyard where, in an order of three identical oil tankers successively made, the errors that appear in the first were repeated in the second, and in the third. Naturally, this shipyard no longer exists. If the daily workload does not allow us to examine the final results of the project, to discuss them and to analyze them, to draw conclusions and to make them known, we cannot learn from what we have done. Regarding this matter, Whitten (1999) suggests implementing dynamics in which authorization to initiate a project is not given if it is not stated beforehand what experiences have been obtained from past projects and how we are going to use them.

- Experimenting in project oriented environments implies considering the next project as something unique, where even the management process can be changed. In a certain way, the experimental project becomes a more bold and attractive task where all the team feels especially proud of collaborating in something which is worthwhile. Each project must contain a certain degree of 
PM process experiment of its own. To the contrary otherwise, we would end up repeating, not mistakes, but attitudes and behavior from previous projects. We would be making a routine of something which is unique and different by definition: the project itself.

Which tools do we have at our disposal to experiment with modifications of how we do things, how we manage projects?

\section{HOW TO CAPTURE KNOWLEDGE IN PM?}

We have already talked about a series of knowledge sources for the post-mortem project evaluation: the tacit knowledge possessed by one's own employees, clients, the best practices pinpointed through the activity of benchmarking, the explicit knowledge codified by the company and the rotation of employees from one post to another within the company itself. We would have to add to this, the results of the non-private $\mathrm{R}+\mathrm{D}$ activity (Administration and Universities) that are published in scientific and technical publications.

What methods, what tools are available on when we want to extract knowledge of the topic that needs to be improved in our project oriented company? How can we prepare our tests in terms of what we want to improve? By means of questionnaires, structured to a greater or lesser degree, we try to reach the conscious behaviour of the group of professionals of the company, or stakeholders. By observing a certain situation we try to discover which elements of this situation are the cause of certain effects. When we think that we know the cause and effect relationship, we formulate a hypothesis, and then the validity of the hypothesis is tested. The simulation tries to bring reality closer to us, in controlled surroundings, overcoming the difficulty of the development of the model. Simulation games are a powerful way to experiment in order to learn about PM.

\section{TWO EXPERIENCES IN DEVELOPING THE TRANSMISSION AND OBTENTION OF KNOWLEDGE IN PROJECT MANAGEMENT}

In this section, some experiences of transmission and reception of tacit knowledge in the PM environment are presented.

The first one of them deals with the development of a Simulation Game. How a work group has been reorganised to be able to improve the original product.

The second one was obtained from real life experience, and it has been developed in collaboration with a small group of companies. It refers to a negotiation application called TRAINER.

\section{Simulation Games in Project Management}

PROSIGA (PROject SImulation GAme) is a simulation game oriented to training in project management. In it, the participant has to assume the role of the project manager, in charge of the project to create of a new bicycle factory. The project 
evolves from the proposal preparation to the execution of the investment. The project development has been funded by EU (Leonardo Da Vinci programme).

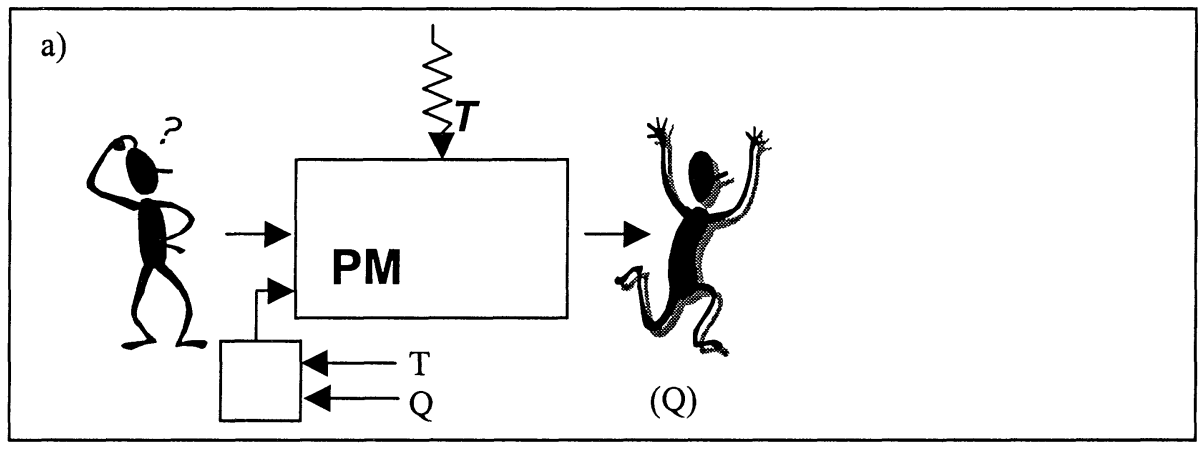

b)
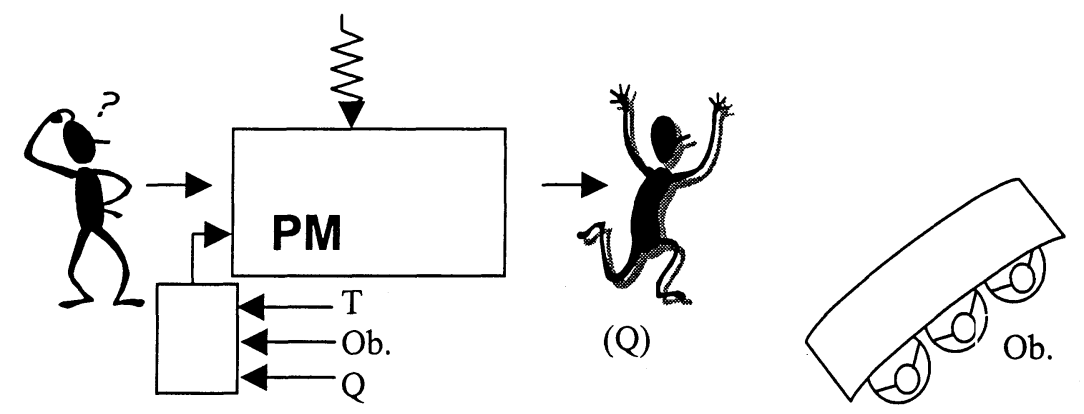

T: Teacher

Ob: Observers

Q: Part. Questionnaires

D: Designers

Figure 1 PROSIGA versions

PROSIGA has evolve through several versions that, as a whole, represent a global effort of 10 year-man, between 1996 and 1998. Figure1.a represents the initial version of the game. Its design corresponds to three inputs coming from tutors, system designers, and opinions gathered from participants in different seminars.

We realised that the designers could not perceive the different situations that the participants were facing when interacting with the application. They were "blind" to this problem because they had got used to playing, therefore, the problem implied a change in the structure of the development group. This change meant the incorporation of an "observation group", dedicated solely to detecting problems affecting the usability of the game (see Figure 2). The problems detected by this group allowed the group of designers to introduce some modifications that led to the new version, PROSIGA 2.0. This new version was more user-friendly, with regards to error messages, menu designs, and help options (see Figure 1.b).

The whole development team had to introduce the acquired knowledge, accepting the "blindness" of the designers and adding the observation group. Figure 2 shows the interaction of the three components (design, training and observation). If we 
want the game to keep going in the future, these dynamics should not be stopped. It would be necessary for the three areas or components to continue working in very close co-ordination.

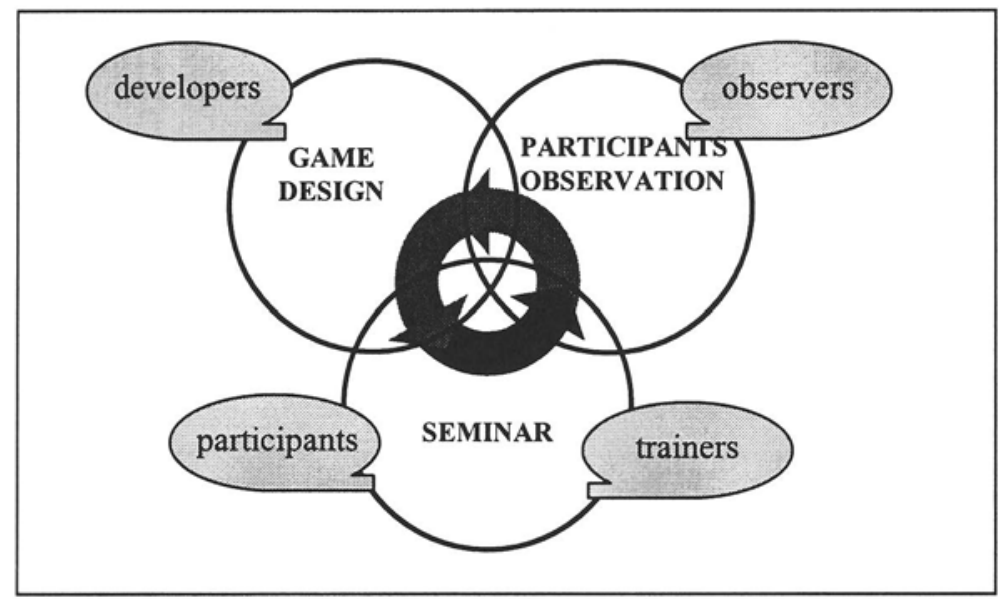

Figure 2 Process development of a simulation game

\section{TRAINER: a negotiation game taken from real life}

TRAINER (TRAIning for NEgotiation through Role-playing) is a Simulation Game that approaches different situations in the life of a contract. The initial idea of the game was extracted from the way of working of a small group of companies that forms a logistic chain which is dedicated to the manufacturing of plastic injection moulds (Cano et al, 1996). At that moment we collaborated with them in the implementation of a project planning and control system and we were very impressed by their own way shown of arranging coordination between the three companies for the task of undertaking their projects.

TRAINER is a game which represents situations where the transmission of tacit knowledge in relation to negotiation processes is shown (Cano et al, 1998). It has been very well-received as a training tool both in the university and in the companies. The plastic injection moulds company has subsequently used it for the training of its junior project managers.

Due to the excellent relations between the logistic company group and the university group we are now introducing modifications in TRAINER. These changes would allow the simulation of actual contract negotiation and its modifications. TRAINER is evolving, from being a training tool to a means for experimenting in negotiation strategies in big contracts.

\section{ACCOMPLISHMENT OF EXPERIMENTS IN PM}

Haho and Smeds (1996) presents a Simulation Laboratory for analysing change process in industries. The application of this to PM process simulation is depicted 
in Figure 3.a. and it would be the basic specification of a PM process Simulation Laboratory.
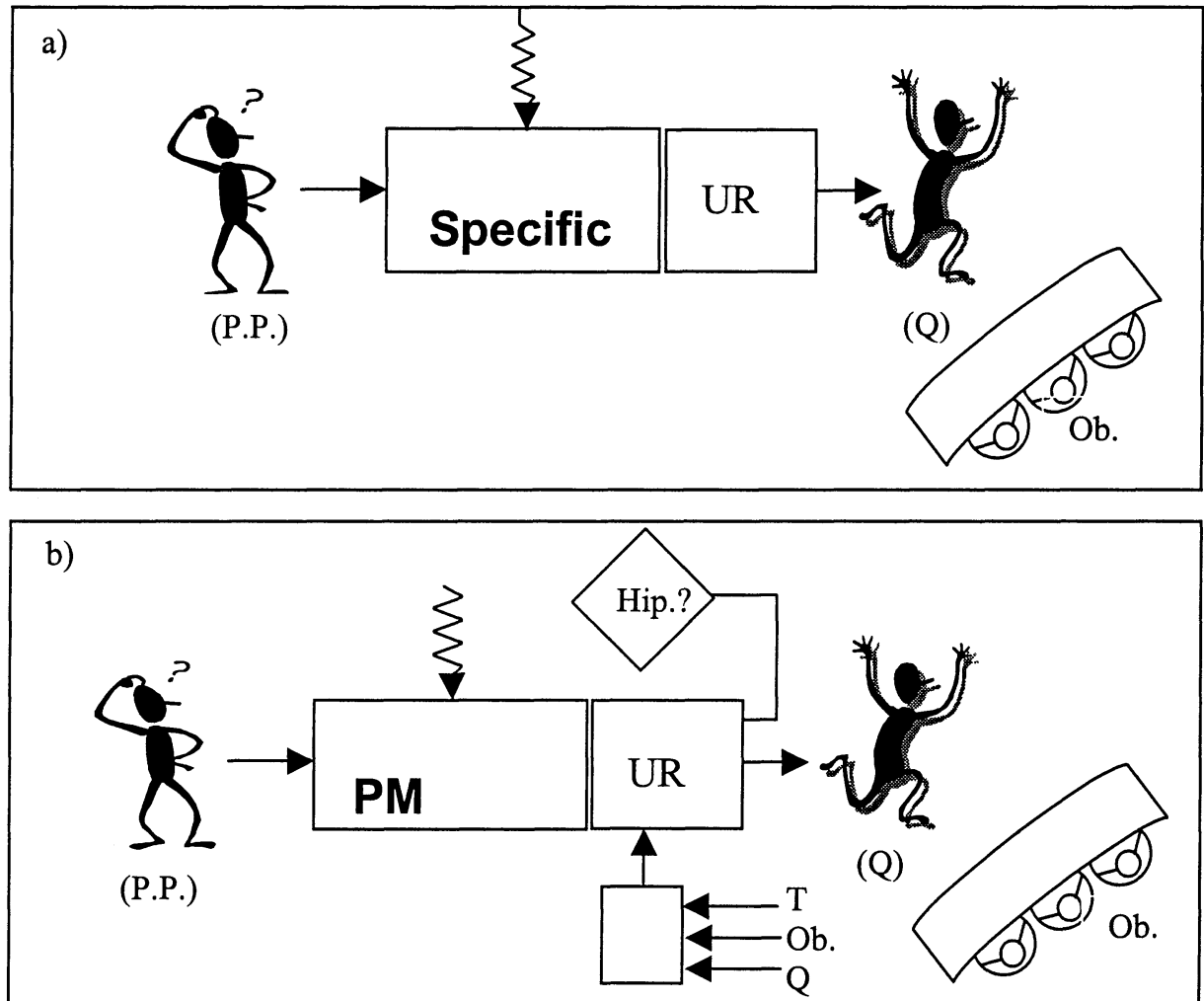

T: Teacher

Q: Part. Questionnaires

D: Designers
P.P.: Participants Profile M: Experiment Director

URR: User Results Register

Ob: Observers

Figure 3 Experiments in PM through simulation games

The elements included in the basic PM process Simulation Laboratory are:

a) Master/teacher: he/she is the director of the situation test we are going to reproduce. $\mathrm{He} / \mathrm{she}$ acts on the participants by changing directives or introducing new situations.

b) Participants: they assume the role that is given to them in the management of the simulated project.

c) The Simulation Game: specifically developed to reproduce the reality of the process (or part of it) of the corresponding project oriented business. The system will include a participants register unit (URR). This will receive the decisions made and will also allow the incorporation of the psychological, cultural and professional profiles of the participants. 
d) Finally, the observation element is formed by a group of spectators, who will be watching the development of the simulation performance and will participate in the debriefing session.

This concept of PM process Simulation Laboratory combines and integrates different research approaches: organizational behavior, psychology, experiment design, sociology or group dynamics, simulation, hypotheses testing as well as PM. The aim of this being in order to obtain the best tacit knowledge found in the "pilots" that will "fly" that PM process simulator.

\section{AN EXPERIENCE OF A SIMULATION GAME AS A TESTING TOOL}

With the previous model in mind (Figure 3.a), we have initiated the very preliminary prototype based on the elements that are depicted in Figure 3.b.

The Simulation Game developed is PROSIGA, version 3.0, with a data acquisition module developed specifically for the game. A group of observers note the incidences of the behaviour of the groups that are playing PROSIGA. Moreover, questionnaires are filled in by the participants. In addition, the tutor reports on the evolution of the session. After we have all the information, we confront several hypotheses on the behaviour of the participants with regards to PROSIGA.

At this point it is important to underline the aspects we have not tackled and the questions we have tried to shed light on:

- How to be able to objectively appreciate the profiles of the participants?

- How to act on the evolution of the game and introduce the situations in which we want the participants to make decisions?

- How to characterise the behaviour of the group when the participants act jointly in the decision making?

- On which field of PM could we act in order to confront hypotheses on expected behaviour of participants?

\section{CONCLUSIONS}

A lot of attention has to be paid to organizational learning in project oriented business. Specifically, Simulation games are powerful tools for revealing tacit knowledge transmission situations.

We feel that a new PM process experimentation arena is emerging: the concept of a PM process Laboratory, suitable for undertaking customized simulations. Considerable work will have to be carried out on the design, managing and interpretation of such events. Nevertheless the concept is perfectly suited to the need of risk avoidance, and indeed is a must in the management of very complex and hazardous projects.

The efforts that are undertaken in this direction will determinate the widespread acceptance of the Project Laboratory concept. 


\section{REFERENCES}

Cano J.L., Sáenz M.J. and Sanz D. 1998. Development of a project simulation game. $14^{\text {th }}$ World Congress on Project Management. Slovenia.

Cano J.L., Cebollada J., Mariscal A., Sáenz M.J. 1998. Development of a Negotiation Simulation Game in the Project Management Environment. IV International Congress of Project Engineering. Cordoba.

Cano J.L., Yubero J.C., Bruna P., Rebollar R., Romanos A. 1996. Implementing project management philosophy in a group of small E.T.O. oriented companies: GTM case. Advances in Production Management Systems. Osaka.

Gareis R. and Huemann M. 1998. International research project PMbenchmarking: benchmarking of the PM-process. Journal of Project Management. Vol.4, No.1.

Garvin D.A.1993. Building a learning organization. Harvard Business Review. JulAug.

Haho P. and Smeds R. 1996. Benefits from using simulation games in business process development. Experiences from a Finnish manufacturing company. Advances in Production Management Systems. Osaka.

Hansen M.T. Nohria N. and Tierner T. 1999. What's your strategy for managing knowledge?. Harvard Business Review. Marc-Apr.

Kleiner A. and Roth G. 1997. How to make experience your company's best teacher. Harvard Business Review. Sept-Oct.

Pinto J.K. and Slevin D.P. 1989. Critical success factors across the project life cycle. Project Management Journal.

Nonaka I. and Takeuchi H. 1995. The Knowledge Creating Company. Oxford University Press. Oxford.

Riis J.O., Smeds R., Johansen J. \& Mikkelsen H. 1996. Games for Organizational Learning in Production Management. Proceeding of $6^{\text {Th }}$ IFIP - APMS'96. Kyoto.

Riis J.O. and Neergaard C. 1995. Managing technology projects: an organizational learning approach. HICSS Conference. Hawai.

Whitten N. 1999. Are you learning from project to project. PM Network. March.

Part 4 - Process for Acquirers.

WEAG TA-13 (1997), Progressive Acquisition

Department of Defense - DoD (1997), DoD Directive Number R5000.2-R

SEI (1996), SA-CMM - Software Acquisition Capability Maturity Model

Statskontoret (1998), SOTIP Vers.2, The Swedish government open telecommunication systems interconnection profile.

Mottram, R. (1995) CCTA - An evaluation of the Full Implementation of the Total Acquisition Process, http://www.ccta.gov.uk/taprep.htm. 


\section{BIOGRAPHY}

Dipl.-Wi.-Ing. Harald Sundmaeker is graduate economic engineer with focus on production technique and industrial management. Since beginning of 1998 member of ATB Institute for Applied Systems Technology Bremen GmbH. He has taken part at different Software Engineering and Procurement projects also funded by the European Community and led several acquisition project assessments as external mentor. His main interests are system analysis and design, quality management and assurance also in the scope of IT procurement projects. 